\title{
COMPARISON OF SURFACE MACROTEXTURE MEASUREMENT METHODS
}

\author{
Nicholas Fisco ${ }^{\mathrm{a}}$, Halil Sezen ${ }^{\mathrm{b}}$ \\ ${ }^{a}$ TranSystems Corporation, Cleveland, Ohio, USA \\ ${ }^{b}$ Department of Civil and Environmental Engineering and Geodetic Science, \\ The Ohio State University, Columbus, Ohio 43210, USA \\ Received 08 Apr 2012; accepted 26 Jun 2012
}

\begin{abstract}
Recent advances in technology allowed for the use of laser-based systems that can directly measure macrotexture properties of various surfaces. Volumetric or sand patch method has historically been used as the main technique for measuring macrotexture. Different available methods do not all measure the same surface properties and often generate different measurements. Thus, it is crucial to determine the most suitable method for measuring surface macrotexture. This paper investigates mean profile depth measurements from three laser based macrotexture measuring devices, including a laser profiler, a laser texture scanner and a circular texture meter. The results are compared with mean texture depth obtained from volumetric sand patch tests. Experiments were conducted to measure macrotexture of 26 laboratory specimens, which included asphalt and Portland cement concrete samples of various type and finish, as well as other common manufactured textured samples. Based on the evaluation of experimental data collected in this study, relationships are recommended to predict standard macrotexture using the mean profile depth data measured by a laser equipment or scanner.
\end{abstract}

Keywords: macrotexture, mean profile depth, mean texture depth; pavement materials, sand patch, laser texture scanner.

Reference to this paper should be made as follows: Fisco, N.; Sezen, H. 2013. Comparison of surface macrotexture measurement methods, Journal of Civil Engineering and Management 19(Supplement 1): S1531-S160.

http://dx.doi.org/10.3846/13923730.2013.802732

\section{Introduction}

Macrotexture is a measurement that can be used to quantify texture, roughness and friction characteristics of the roads and other surfaces. Road surface texture is important to know because it affects many factors significant in the design phase of a project. The surface texture is related to and may be used in determination of noise emission, friction, rolling resistance, splash and spray, and tire wear which all contribute to the design and performance of a roadway. Physical properties of pavement materials have been investigated in the field (Kim et al. 2011).

The volumetric or sand patch method (ASTM E 965 2006) has been historically used as the main technique for measuring pavement macrotexture. Macrotexture can be defined as surface irregularities of wavelength varying between approximately 0.5 and $50 \mathrm{~mm}$. The texture depth of the surface on which the sand patch test is performed, is represented by mean texture depth (MTD). Recent advances in technology have allowed for the development of laser based systems that can directly measure macrotexture, not only statically, but also at different speeds. These different methods do not all measure the same surface properties, though, and often generate different measurements (Flintsch et al. 2003, 2005). Because of these differences, it is crucial to determine the most suitable method for measuring pavement macrotexture. In this research, several methods were used to determine texture characteristics of laboratory specimens with different surface characteristics. Results from sand patch tests, computed tomography scanning, laser profile scanning, laser texture scanning and circular texture meter scanning were evaluated and compared.

\section{Laboratory samples}

Samples ranging from asphalt and Portland cement concretes of different finish and mix design, and with various other textured surfaces were constructed or obtained. Description of samples and test results can be found in Fisco (2009) and Fisco and Sezen (2012).

\subsection{Asphalt samples}

Three different $356 \mathrm{~mm}$ diameter and $76 \mathrm{~mm}$ thick asphalt samples were created by manually compressing the samples using a hand tamp in a metal mold. Stone matrix asphalt (SMA, Medium Grade) sample is composed of \#7 aggregate, with an approximate particle diameter of $4.8 \mathrm{~mm}$. SMA samples have a relatively rough surface texture but less than that of the coarse graded asphalt. This type of asphalt is commonly used as a surface course for high-volume interstate roads due to its smoothness, drainage, friction, rut resistance and noise control characteristics. Coarse Graded Asphalt Concrete or open graded sample is composed of \#57 aggregate, with particle sizes 
ranging from 4.8 to $25.4 \mathrm{~mm}$, and contains large surface irregularities. Sample appears very porous and has a very rough surface texture. The air voids in the open graded asphalt provide for excellent drainage characteristics, which leads to a reduction in splash and spray. Dense Graded Asphalt sample is composed of \#8 limestone with an approximate aggregate size of $2.5 \mathrm{~mm}$ and seems very dense. Minimal voids between aggregate and binder appear to exist and though it has a relatively coarse surface texture. It has the smoothest surface of the three asphalt samples used in this research. This type of asphalt is, when designed correctly, relatively impermeable and appropriate for use in all pavement layers and under all traffic conditions.

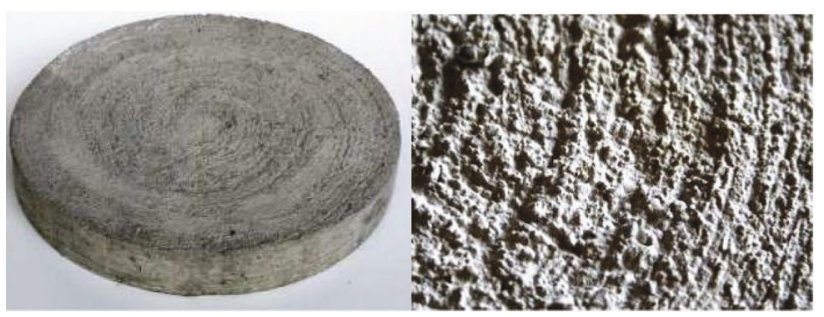

Turf drag Portland cement concrete sample

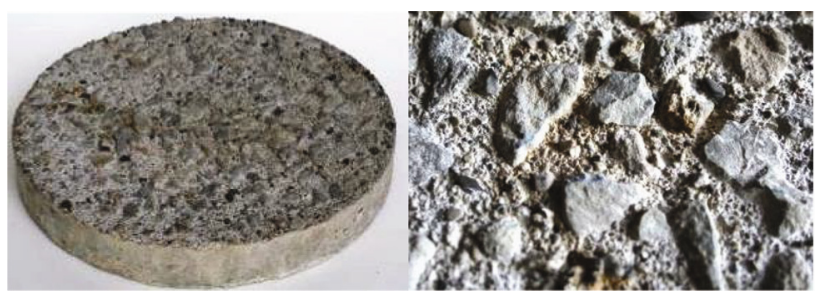

Exposed aggregate Portland cement concrete sample

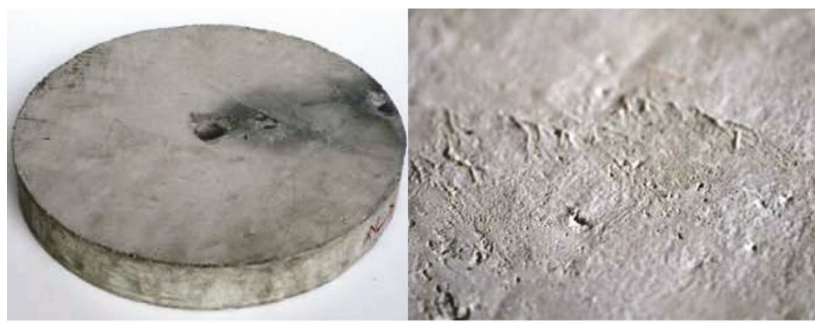

Smooth Portland cement concrete sample

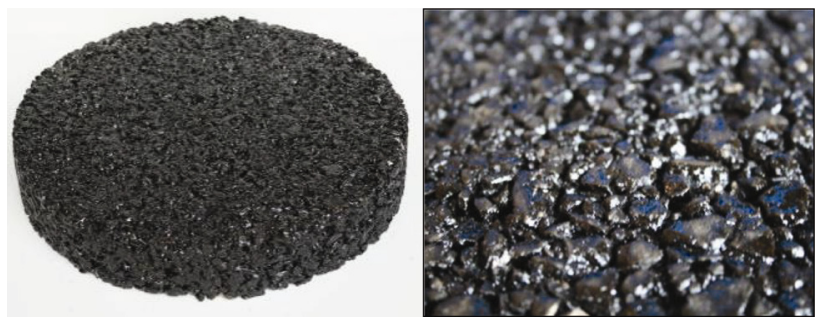

SMA asphalt sample

Fig. 1. Selected samples and surface textures

\subsection{Concrete samples}

Concrete samples were $305 \mathrm{~mm}$ in diameter and $38 \mathrm{~mm}$ thick. For all samples, the finish was done in a radial or circular pattern to mimic a straight pattern as the samples spin during experiments. Two samples of each finish, except for burlap layover, were made for consistency.
Burlap Drag specimen was prepared by dragging a moistened piece of coarse burlap (AASHTO M182 Class 2) along surface, creating $1.6 \mathrm{~mm}$ deep striations. This finish is usually used on roadways with lower travel speeds (less than $70 \mathrm{~km} / \mathrm{h}$ ) and is less costly and quieter than most tined finishes (Hoerner et al. 2003). Artificial Turf Drag was prepared using an inverted piece of artificial turf with 6.4-mm long blades and 9000 blades per $\mathrm{ft}^{2}$ drug along surface to create striations. Research has found that this finish provides better surface friction and noise qualities. Longitudinal Broom specimen was created using a hand broom with hair bristles drug along surface, creating 1.6 to $3.2 \mathrm{~mm}$ deep striations. This finish has been found to be a less costly and quieter alternative to tined finishes and is adequate for roadways with travel speeds up to $70 \mathrm{~km} / \mathrm{h}$ (Hoerner et al. 2003).

A metal trowel was used to make 3.2 to $6.4 \mathrm{~mm}$ deep, $3.2 \mathrm{~mm}$ wide grooves spaced $19 \mathrm{~mm}$ at a radius of $127 \mathrm{~mm}$ in Transverse Tine sample. This type of tining is cost effective and improves a pavement's friction characteristics because the grooves are highly efficient at quickly removing surface water. A downside to this finish is that it increases pavement noise. Metal trowel was used to get the concrete surface of Smooth Finish sample as smooth as possible. This finish is typically used indoors on surfaces such as slabs. This finish is not ideal for pavements, due to its low surface texture and low friction characteristics.

A retarder was sprayed onto the surface of the Exposed Aggregate sample and the top mortar was later removed leaving the top layer or aggregate exposed. Advantages of this finish type of pavement surface include low noise, exceptional high-speed skid resistance, low splash and spray, and good surface durability. The specimen Burlap Layover was created by placing a piece of moistened coarse burlap (AASHTO M182 Class 2) on top of sample surface for 24 hours and then removed. Texture of random thatched burlap pattern left on sample surface. Figure 1 shows three different concrete samples used in this research.

\subsection{Other samples}

Perm-a-Mulch Rubber Stepping Stone was a round, discshaped artificial stepping-stone made of recycled rubber pellets. The disc was $330 \mathrm{~mm}$ in diameter, $32 \mathrm{~mm}$ thick, and was very porous. The surface of the disc was moderately coarse due to the jagged rubber pellets that make up its composition. USG Tivoli Ceiling Tile was a square wood fibre ceiling panel that is $305 \mathrm{~mm}$ on each edge and was $13 \mathrm{~mm}$ thick. The surface was smooth with random $1 \mathrm{~mm}$ indentations for aesthetics. USG Cheyenne Ceiling Panel was a $610 \mathrm{~mm}$ square ceiling panel that was made of slag wool and various minerals such as perlite, silicate and kaolin. Texture of the tile was very rough with numerous sharp peaks and irregularities. Sandpaper Discs of grit 50,60 , and 80 were used. The 50-grit sandpaper is coarser than the 60 grit, which is much coarser than the 80 grit. Granite Stepping Stone was a commercial $305 \mathrm{~mm}$ square stone with a $13 \mathrm{~mm}$ thickness. The stone 
had two distinct surfaces. One was very smooth while the other was relatively rough.

\section{Sand patch test method}

In sand patch method or volumetric patch method, a fixed volume of sand or glass spheres is carefully poured on a test location. Using a flat disk, the sample is spread out in a circular motion while trying to keep the sand or glass spheres evenly distributed until the disk comes in contact with the material surface. The patch area is calculated using the average diameter of the circular patch. By dividing the volume of material by the area covered, the average depth of the layer or mean texture depth (MTD) of the surface is calculated from Eqn (1) specified in ASTM E 965 (2006):

$$
\mathrm{MTD}=\frac{4 \cdot V}{\pi \cdot D^{2}},
$$

where: $V$ is volume of sand or glass spheres; and $D$ is average patch diameter. Figure 2 shows four sand patch tests performed on an exposed Portland cement concrete sample using $12.5 \mathrm{~mL}$ of fine sand for each test.

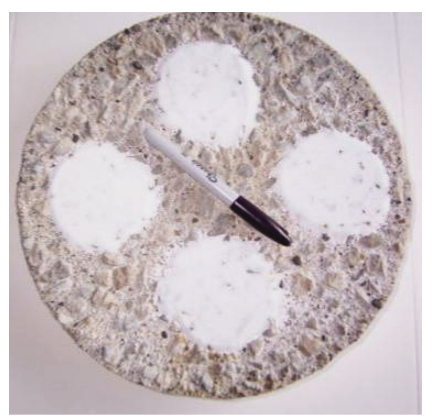

Fig. 2. Volumetric sand patch tests performed on an exposed aggregate concrete sample

\section{Computed tomography scanning}

The use of digital imagery, especially computed tomography (CT) scans, to measure three-dimensional surface characteristics of pavements has shown much promise. CT scans can help to better understand sample surface characteristics. Abbas et al. (2007) applied the results of CT scans to measure the mean profile depth (MPD) of concrete field cores in accordance with ASTM E 1845 (2005). Similarly, Kutay and Aydilek (2007) used CT scans to quantify the effects of moisture on asphalt structure. CT scanning is typically employs the use of tomography, which involves the process of sectioning. Two-dimensional x-rays or "slices" are combined using algorithms to make a three-dimensional image of the object being scanned around a single axis of rotation. In this research the specimen was placed on a bed that moves the specimen through the gantry, or opening, of the machine. As the specimen passes through, the gantry rotates around the bed and specimen (single axis of rotation) and takes two-dimensional $\mathrm{x}$ ray images of the specimen. In this research, Siemens SOMATOM Sensation CT Scanner was used. This scanner has detector arrays which scan 64 slices per rotation. The gantry takes 0.33 seconds to do a full rotation $(180 \mathrm{rpm})$ with a total scan time of under five minutes.

After the samples were scanned, the two-dimensional images were reconstructed using the TeraRecon Aquarius imaging software. A three-dimensional (3-D) rendering of the entire sample was produced for each specimen. In addition, a three-dimensional rendering was made of a $100 \mathrm{~mm}$ square area of the surface (Figures 3d and $3 \mathrm{e}$ ). Though the use of CT imaging was limited during this study, it showed great promise in obtaining accurate representations of the sample surface and profile, as well as the internal structure. A limitation of this method, however, is that cores are required to perform laboratory tests on, making it impractical for field use at this point.

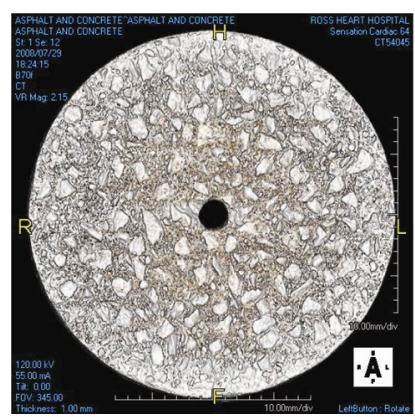

a)

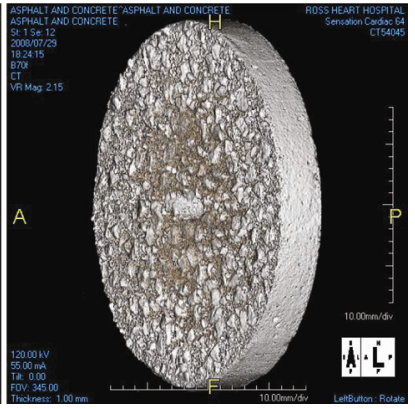

b)

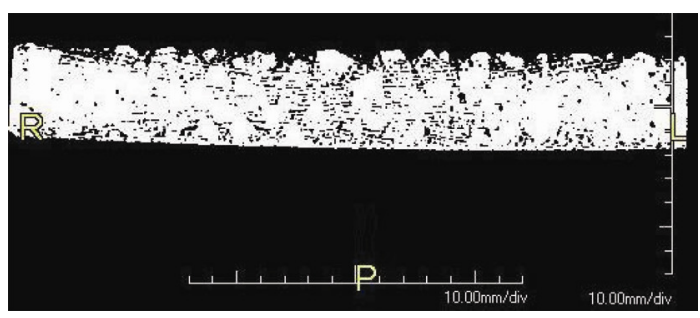

c)

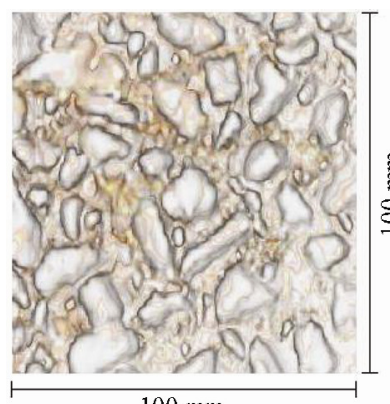

$100 \mathrm{~mm}$

d)

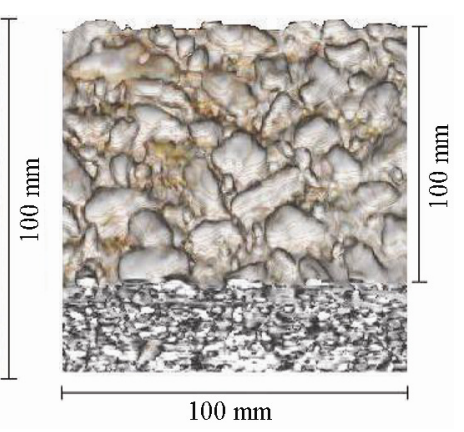

e)
Fig. 3. Exposed aggregate concrete sample CT scan rendering: a) top view; b) side view; c) two-dimensional CT scan slice; d) top view; and e) side view of $100 \mathrm{~mm}$ square sections

\section{Laser profile scanning}

In recent years, different laser tools have been successfully used to measure the surface macrotexture of highway pavements (Choubane et al. 2002; Sezen et al. 2008; Byrum et al. 2010). In this project, a laser profiler provided by Dynatest (Selcom Optocator 2008-180/390) was used to measure the macrotexture of test samples. The laser had a measuring range of $180 \mathrm{~mm}$ with a standoff of 
$390 \mathrm{~mm}$. It had a sampling rate of $62.5 \mathrm{kHz}$ with $45 \mathrm{mi}-$ crons resolution. The laser system was mounted on the front end of a van, and was housed in a steel box approximately $305 \mathrm{~mm}$ off the ground (Fig. 4).

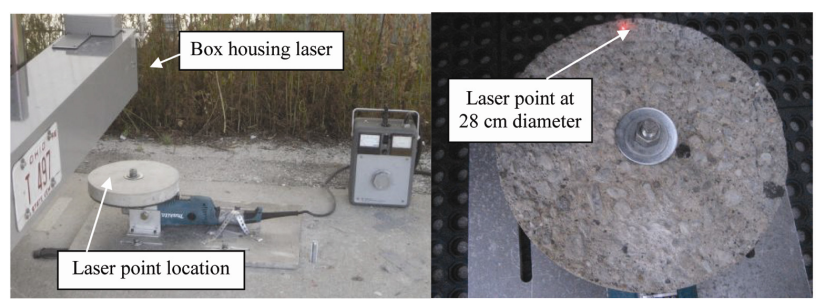

Fig. 4. Test apparatus for laser profiler

An apparatus was built to spin the samples to simulate the Dynatest laser profiler driving over the surface of the sample. To do this, a Makita 7,500 RPM metal grinder was attached to an aluminium plate, which was bolted to a concrete slab (Fig. 4). Samples were bolted to the aluminium plate and grinder. To make all tests comparable, readings were taken on each sample for a set total distance of $152 \mathrm{~m}$. An average of all MPD values over the $152 \mathrm{~m}$ section was then taken and used as the average MPD at the set speed in compliance with ASTM E 1845 (2005).

\section{Laser texture scanning}

Portable laser macrotexture measurement devices have recently been developed for determining pavement texture. The laser texture scanner system produced by Ames Engineering is used in this research (Ames 2009). This device scans the material surface in multiple line scans to measure the mean profile depth (MPD), estimated texture depth (ETD), and a 3-D image of the material surface. The scanner is capable of scanning an area that is $101.6 \mathrm{~mm}$ long and $76.2 \mathrm{~mm}$ wide and has a maximum capacity of 1200 lines, which equates to an average spacing of $0.0635 \mathrm{~mm}$ between scan lines. The laser has a standoff distance of $42 \mathrm{~mm}$, vertical and horizontal sampling resolutions of $0.015 \mathrm{~mm}$, and profile wavelength ranging from $0.03 \mathrm{~mm}$ to $50 \mathrm{~mm}$. Four different quarters were tested on each sample, with the scanner set to run
100 lines. 3-D rendering of the exposed aggregate concrete sample is shown in Figure 5.

\section{CT meter scanning}

Circular texture meter (CT meter) is a surface macrotexture measurement device that uses a laser to measure the MPD of a surface along a circular track with a fixed diameter of $284 \mathrm{~mm}$. The device used in this study was the Nippo CTM manufactured by the Nippo Sangyo Co. of Japan (Abe et al. 2001). It uses a $670 \mathrm{~mm}$ wavelength laser that has a spot size of $70 \mu \mathrm{m}$, a measuring range of $30 \mathrm{~mm}$, and a vertical resolution of $3 \mu \mathrm{m}$. The arm on which the laser is mounted spins at a speed of $7.5 \mathrm{rpm}$ and the laser samples at a rate of 1,024 samples per rotation. The sample is split radially into eight $112 \mathrm{~mm}$ arcs of equal length (labelled A through H) and the MPD of each arc is determined. These eight measurements are then averaged to give an overall MPD for the entire surface and produce a 2-D surface profile.

All specimens described above were placed on the ground or in a testing rig and the CT meter was then placed above each specimen. Surface of each specimen was scanned three times along the same 284-mm diameter circular track, with an MPD reading and a 2-D surface profile being recorded for each test. As an example, the measured surface profile of the exposed aggregate sample is shown in Figure 6.

\section{Comparison of surface macrotexture methods}

In this research, four main macrotexture testing methods are compared. The Dynatest laser profiler measures texture by obtaining MPD readings for a 2-D profile of the surface in the direction of travel. These MPD values must be transformed into estimated texture depth (ETD) so that they can be compared to MTD measurements from the sand patch method. The Ames laser scanner measures a 3 -D profile of a $102 \times 76 \mathrm{~mm}$ area by making repeated passes with the laser and compiling the 2-D profile data for each pass. From these compiled profiles, an ETD value is calculated, which can be compared directly to the MTD value.

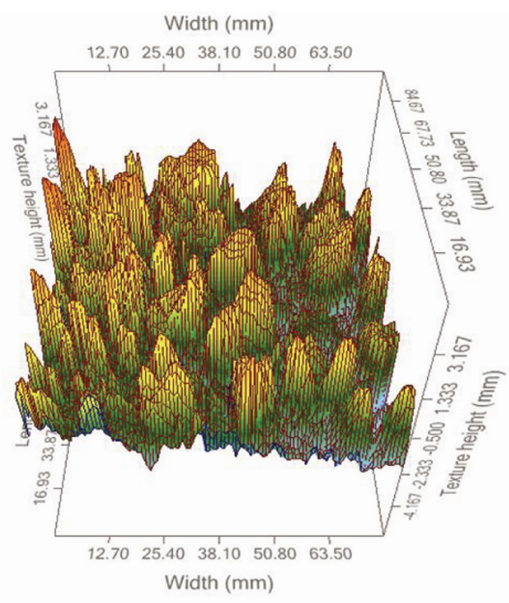

b)

Fig. 5. 3-D surface rendering of the exposed aggregate concrete sample obtained from laser texture scanner: a) top; and b) side views 


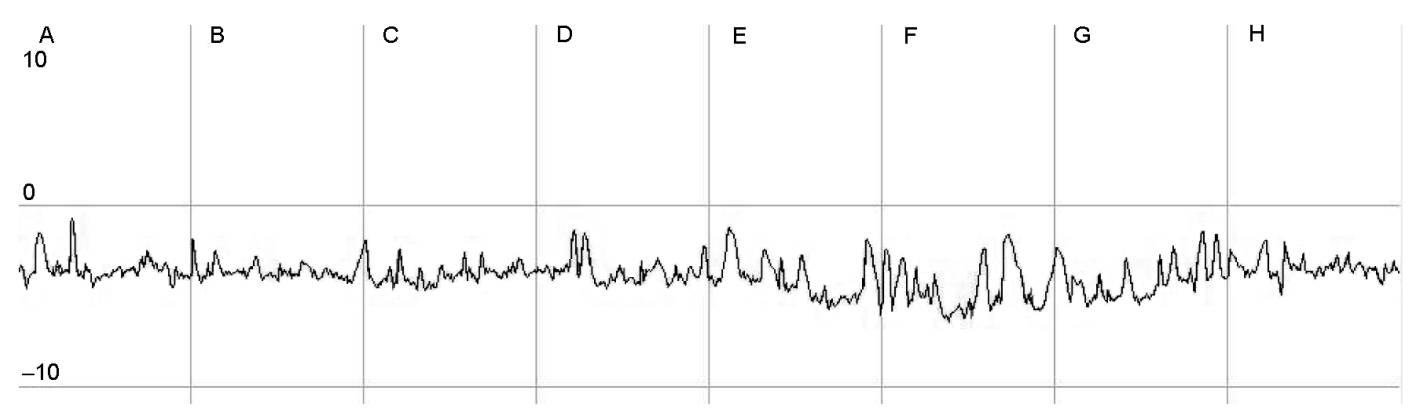

Fig. 6. Surface profile of exposed aggregate sample measured by the CT meter scanner (in mm units)

The CT meter is another laser based method to measure 2-D texture and MPD along a circular track. These MPD values are also transformed into ETD so that they can be compared to measurements from the sand patch tests and other methods. A disadvantage of this method is that it only measures texture along a single 2-D profile and may, therefore, miss what's happening on the other parts of the surface, which may be rougher or smoother than the track being measured. The features of the surface texture that are missed by the CT meter can be captured using the 3-D texture measurement methods of the sand patch and Ames scanner. The main disadvantage of 2-D CT meter and 3-D Ames laser scanner is their limitation on the size of scanned area. These two tools can measure the texture of a relatively small surface. They are not practical to measure the macrotexture of large pavement segments. 2-D Dynatest laser profiler can be handy to measure the macrotexture of large surfaces.

The 2-D testing may have problems with porous, open-graded, and highly textured surfaces. Because these surfaces have large voids, it is unlikely that the 2-D profiler captures all the highest peaks and the lowest valleys of the voids. Rather, the profile captures some of the extremes but, for the most part, captures points in between, thus underestimating the actual texture. Similarly, sand patch test cannot accurately predict the texture of very rough or porous surfaces because even distribution of sand or glass spheres may not be possible.

\subsection{Texture depth from laser profiler and laser scanner}

The mean profile depth (MPD) value provided by the Dynatest laser profiler is obtained as the average of MPD values calculated at user specified intervals. The MPD value is calculated using an algorithm based on ASTM specification E 1845 (2005). Per ASTM E 1845, the profile is divided into segments with a base length of $100 \mathrm{~mm}$. The slope of each segment and the height of the highest peak are determined. The difference between the height and the average level of the segment is then calculated. The average values of these differences for all segments making up the measured profile are finally reported as the MPD for the entire pavement section.

In order to compare the MPD to mean texture depth (MTD) from sand patch test, a transformation equation is used to reclassify the MPD as an Estimated Texture Depth (ETD). Eqn (2) should yield ETD values which are close to the MTD values obtained from the volumetric technique according to ASTME 965 (2006) and ASTM E 1845 (2005) in mm units:

$$
\mathrm{ETD}=0.2+0.8 \cdot \mathrm{MPD} .
$$

After each laser scan, the average MPD for the scanned sample area was reported by the Ames laser scanner. The average MPD was then converted into ETD by using Eqn (2) as recommended by Ames (2009).

\subsection{Texture depth from CT meter}

The MPD values obtained from each of the three runs along the same circular track on a sample were converted to MTD using Eqn (3) presented in ASTM E2157 (2005) in $\mathrm{mm}$ units. For the purpose of this study, this MTD will be referred to as ETD to avoid confusion when the sample macrotexture from different methods are compared below. The ETD values from three runs were averaged to get an overall average value of the ETD for each sample. Since most of the samples were only $305 \mathrm{~mm}$ in diameter and the CT meter took measurements at a diameter of $284 \mathrm{~mm}$, it is possible that macrotexture near the edges can be slightly different (edge effects):

$$
\mathrm{MTD}=0.947 \cdot \mathrm{MPD}+0.069 \text {. }
$$

\subsection{Comparison of macrotexture from different methods}

Table 1 shows the MTD values from volumetric sand patch tests, along with the ETD values, calculated from Eqns (2) and (3) using the MPD values from the Ames laser texture scanner, Dynatest laser profiler, and CT meter tests, respectively. Data reported in Table 1 for the laser profiler corresponds to a laser speed of $40 \mathrm{~km} / \mathrm{h}$. Table 1 shows that the open graded and SMA asphalt samples, and exposed aggregate concrete samples have the highest MTD and ETD values. Conversely, the smooth granite samples had the smallest average MPD and ETD values. Of the concrete samples, the exposed aggregate samples were the roughest, while the smooth finished samples had the smallest MPD and ETD values. For the sandpaper samples, the average MPD and ETD decreased as grit number increased, which is expected, since the fineness of sandpaper increases as the grit number increases.

Table 1 shows that, in general, the Ames laser texture scanner results are comparable with the sand patch MTD than the results from Dynatest laser profiler and CT 
meter ETD. The average percent difference between the sand patch data (MTD) and other methods (ETD) was also calculated. When the average was taken, the porous samples (e.g. rubber stepping-stone and open graded asphalt) were not taken into account due to the potential inadequacy of the sand patch method on those surface types. As mentioned above, when the sand is poured onto the porous surface, the sand flows in the voids, giving a smaller value for the MTD and, therefore, overestimating it. This is one advantage of using a laser based system. Also, the asphalt samples were not taken into account for the Dynatest laser profiler comparisons. This was done because of the problem of changing of surface texture while the samples were spun at high speeds and could not be adequately restrained. The overall average percent difference for the Ames laser texture scanner, Dynatest laser profiler and CT meter was $28 \%, 36 \%$ and $37 \%$, respectively.

The percent differences were averaged and classified according to type of sample (concrete or nonpavement) and texture (overly rough with MTD more than $1.90 \mathrm{~mm}$ or overly smooth with MTD less than $0.25 \mathrm{~mm}$ ). It was found that the laser texture scanner had the smallest percent difference for the concrete breakdown, while the CT meter had the least percent difference for the non-pavement and smooth samples.

\section{Analysis of test results}

The results from each method were analysed by comparing the MPD data from each method with MTD values from the sand patch tests. A best-fit line and coefficient of correlation were calculated for the two methods. The closer the coefficient of correlation is to 1.0, the better the correlation, and the better the method is (Moore et al. 2009). Many researchers, including Prowell and Hanson (2005), Flintsch et al. (2005), Meegoda et al. (2005), and Wang et al. (2011) used this technique to compare macrotexture methods, such as the CT meter and laser profilers.

Figure 7a shows the relationship between the MTD values from sand patch tests and MPD data obtained from the laser texture scanner. The MPD measurements obtained from the laser profiler at a speed of $40 \mathrm{~km} / \mathrm{h}$ were plotted against sand patch MTD to determine how well the data correlated. A similar linear relationship was obtained for the sand patch MTD and CT meter MPD data. The equations relating the sand patch MTD data and the MPD data from the laser texture scanner, laser profiler and CT meter are shown and compared with the corresponding ASTM equations in Table 2.

Table 1. Average MTD from sand patch tests compared with average ETD and percent difference for Ames laser texture scanner, Dynatest laser profiler at $25 \mathrm{mph}$ speed, and CT meter

\begin{tabular}{l|c|c|c|c|c|c|c}
\cline { 2 - 8 } & Sand patch & \multicolumn{2}{|c|}{ Laser scanner } & \multicolumn{2}{c|}{ Laser profiler } & \multicolumn{2}{c}{ CT meter } \\
\cline { 2 - 8 } & MTD & \multicolumn{2}{|c|}{ ETD } & \multicolumn{2}{c}{ ETD } & \multicolumn{2}{c}{ ETD } \\
\cline { 2 - 8 } & $\mathrm{mm}$ & \multicolumn{2}{|c|}{$\mathrm{mm}(\%)$} & \multicolumn{2}{c}{$\mathrm{mm}(\%)$} & \multicolumn{2}{c}{ mm (\%) } \\
\hline 50 Grit Sandpaper & 0.305 & 0.389 & $(24)$ & 0.505 & $(49)$ & 0.224 & $(31)$ \\
\hline 60 Grit Sandpaper & 0.337 & 0.345 & $(2.3)$ & 0.430 & $(24)$ & 0.198 & $(52)$ \\
\hline 80 Grit Sandpaper & 0.237 & 0.345 & $(37)$ & 0.484 & $(69)$ & 0.154 & $(42)$ \\
\hline Alpine Tile & 0.708 & 0.677 & $(4.5)$ & 0.708 & $(0)$ & 0.584 & $(19)$ \\
\hline Broom 1 & 1.372 & 1.103 & $(22)$ & 0.776 & $(56)$ & 0.685 & $(67)$ \\
\hline Broom 2 & 1.324 & 1.043 & $(24)$ & 0.810 & $(48)$ & 0.656 & $(67)$ \\
\hline Burlap Drag 1 & 0.767 & 0.787 & $(2.6)$ & 0.654 & $(16)$ & 0.748 & $(3)$ \\
\hline Burlap Drag 2 & 0.738 & 0.845 & $(14)$ & 0.688 & $(7)$ & 0.795 & $(7)$ \\
\hline Burlap Layover & 0.354 & 0.465 & $(27)$ & - & - & 0.423 & $(18)$ \\
\hline Cheyenne Tile & 2.498 & 1.878 & $(28)$ & 2.334 & $(7)$ & - & - \\
\hline Dense Graded Asphalt & 0.703 & 0.636 & $(10)$ & 2.532 & $(113)$ & 1.382 & $(65)$ \\
\hline Exposed Aggregate 1 & 2.492 & 1.869 & $(29)$ & 1.934 & $(25)$ & 1.966 & $(24)$ \\
\hline Exposed Aggregate 2 & 2.486 & 1.836 & $(30)$ & 1.954 & $(24)$ & 1.714 & $(37)$ \\
\hline Open Graded Asphalt 1 & 7.885 & 2.682 & $(99)$ & - & - & 3.229 & $(84)$ \\
\hline Open Graded Asphalt 2 & 11.85 & 2.276 & $(136)$ & - & - & 5.508 & $(73)$ \\
\hline Radial Tine 1 & 2.206 & 1.790 & $(21)$ & 1.948 & $(12)$ & 1.101 & $(67)$ \\
\hline Radial Tine 2 & 2.187 & 1.761 & $(22)$ & 2.286 & $(4)$ & 0.814 & $(92)$ \\
\hline Rough Granite & 0.364 & 0.608 & $(50)$ & 0.606 & $(50)$ & 0.479 & $(27)$ \\
\hline Rubber Stepping Stone & 3.259 & 1.049 & $(103)$ & 2.936 & $(10)$ & 0.959 & $(109)$ \\
\hline SMA & 2.864 & 1.582 & $(58)$ & 3.223 & $(12)$ & 1.654 & $(54)$ \\
\hline Smooth 1 & 1.855 & 1.296 & $(36)$ & 2.222 & $(18)$ & 0.322 & $(55)$ \\
\hline Smooth 2 & 0.166 & 0.324 & $(65)$ & 0.329 & $(66)$ & 0.236 & $(39)$ \\
\hline Smooth Granite & 0.223 & 0.327 & $(38)$ & 0.349 & $(44)$ & 0.104 & $(104)$ \\
\hline Tivoli Panel (12") & 0.130 & 0.265 & $(68)$ & 0.403 & $(103)$ & 0.249 & $(54)$ \\
\hline Turf Drag 1 & 0.234 & 0.341 & $(37)$ & 0.417 & $(56)$ & 0.536 & $(44)$ \\
\hline Turf Drag 2 & 1.131 & 1.008 & $(12)$ & 0.728 & $(43)$ & 0.959 & $(32)$ \\
\hline & & & & & & & \\
\hline
\end{tabular}


a)

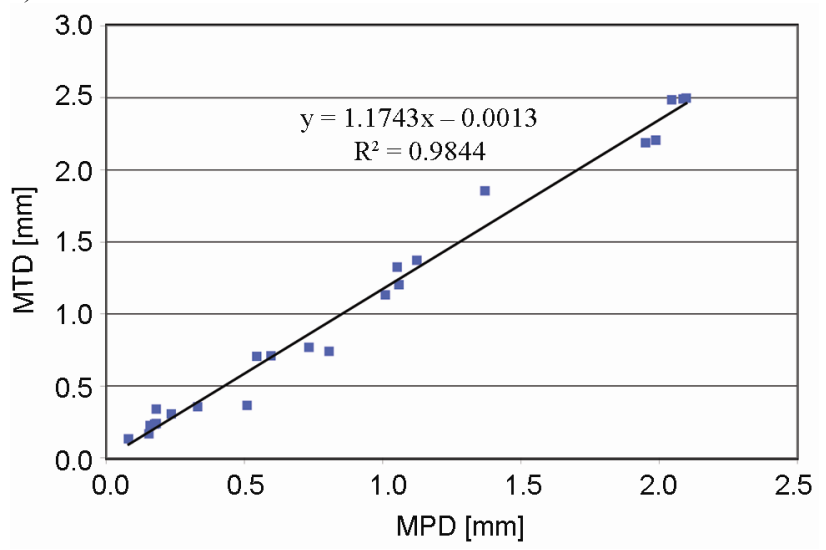

b)

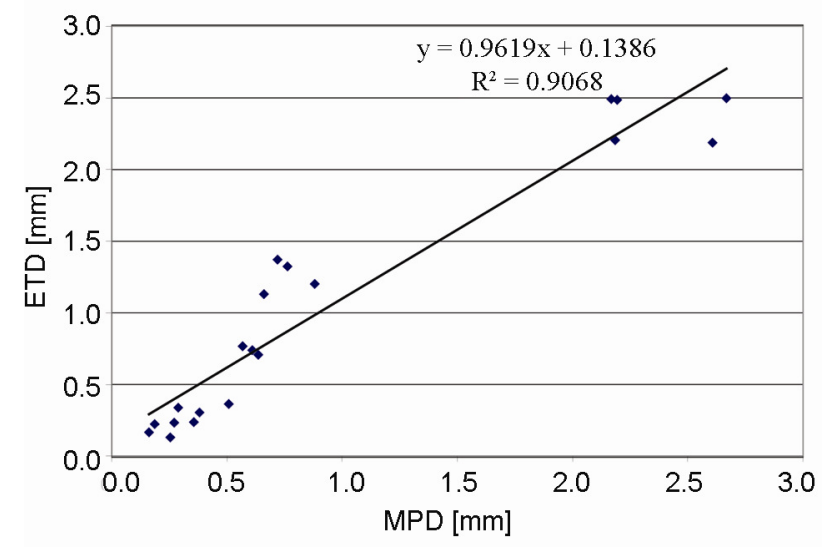

Fig. 7. Linear relationship between MTD from sand patch test and: a) laser scanner; and b) laser profiler

Table 2. Summary of proposed macrotexture relations and ASTM standard equations (in mm units)

\begin{tabular}{l|c|c}
\hline \multicolumn{1}{c|}{ Method } & ASTM Standards & Proposed equations \\
\hline Laser scanner & $0.8 \cdot \mathrm{MPD}+0.2$ & $1.17 \cdot \mathrm{MPD}$ \\
\hline Laser profiler & $0.8 \cdot \mathrm{MPD}+0.2$ & $0.96 \cdot \mathrm{MPD}+0.139$ \\
\hline CT Meter & $\begin{array}{c}0.947 \cdot \mathrm{MPD}+ \\
0.069\end{array}$ & $1.25 \cdot \mathrm{MPD}+0.078$ \\
\hline \multirow{2}{*}{ Overall } & $1.1 \cdot \mathrm{MPD}+0.082$ \\
\cline { 2 - 3 }
\end{tabular}

\section{Conclusions}

Macrotexture of 26 laboratory specimens were obtained using: 1) sand patch test method; 2) x-ray computer tomography (CT) scanner; 3) laser profiler; 4) laser texture scanner; and 5) laser circular texture meter (CT meter). The majority of the analyses discussed in this paper was done with the assumption that the sand patch test measurement (MTD) was the most accurate predictor of surface macrotexture. This may be incorrect since there is no way of obtaining a truly accurate measurement of pavement macrotexture. For example, it was concluded in this research that sand patch test should not be used to predict the macrotexture of porous surfaces. If a new equipment or measurement method is developed in the future, the relations based on MTD can be updated using the new method as it is done in this study.
Whenever practical, laser texture scanner can be used to collect 2-D and 3-D surface macrotexture data. Laser scanner is probably the most suitable device for the measurement of surface macrotexture due to various limitations of each method investigated in this paper. It was found in this research that reasonably accurate MPD can be obtained by laser scanning within 60 seconds, which is typically less than the time required for conducting a sand patch test. The laser texture scanner MPD was found to have a higher correlation to the MTD from sand patch tests. Due to the time and traffic control needed to perform laser texture scanning, the 2-D laser profiler may be superior due to its quickness, relative ease of operation, and relative accuracy of predicting surface macrotexture.

The relations between MTD and MPD were found to differ from the equations presented in ASTM E 1845 (2005) and ASTM E 2157 (2005). The simplified equations shown in Table 2 are proposed for the laser texture scanner, laser profiler and CT meter investigated in this research. A general equation is also recommended to predict standard macrotexture (MTD) from the MPD measured by a scanner or laser equipment.

\section{Acknowledgements}

Funding for this research was provided by the Ohio Department of Transportation (ODOT); this is gratefully acknowledged. The contents of this paper reflect the view of the authors and do not necessarily reflect the official views or policies of the sponsor or other entities. Asphalt and concrete samples were created by Kokosing Materials Inc. and by ODOT, respectively. The CT meter was provided for use by Burns, Cooley, Dennis, Inc. of Ridgeland, Mississippi through the Federal Highway Administration loan program. The authors would like to thank these entities and the Ohio State University Center for Automotive Research, Ames Engineering Inc., and Dynatest.

\section{References}

Abbas, A.; Kutay, M. E.; Azari, H.; Rasmussen, R. 2007. Three-dimensional surface texture characterization of Portland cement concrete pavements, Computer-Aided Civil and Infrastructure Engineering 22(3): 197-209. http://dx.doi.org/10.1111/j.1467-8667.2007.00479.x

Abe, H.; Henry, J. J.; Tamai, A.; Wambold, J. 2001. Measurement of pavement macrotexture with circular texture meter, Transportation Research Record 1764: 201-209. http://dx.doi.org/10.3141/1764-21

Ames. 2009. Ames engineering laser texture scanner user manual. Ames Engineering, Ames, Iowa, 4-8.

ASTM E 1845. 2005. Standard practice for calculating pavement macrotexture mean profile depth. Book of ASTM standards, 2001 (Reapproved 2005). ASTM International.

ASTM E 2157. 2005. Standard test method for measuring pavement macrotexture properties using the circular track meter. Book of ASTM standards, 2001 (Reapproved 2005). ASTM International.

ASTM E 965. 2006. Standard test method for measuring pavement macrotexture depth using a volumetric technique. Book of ASTM standards, Vol. 04.03, 1996 (Reapproved 2006). ASTM International. 
Byrum, C. R.; Raymond, C.; Swanlund, M.; Kazmierowski, T. 2010. Experimental shortwavelength surface textures in Portland cement concrete pavements, Transportation Research Record 2155: 170-178. http://dx.doi.org/10.3141/2155-18

Choubane, B.; McNamara, R. L.; Page, G. C. 2002. Evaluation of high-speed profilers for measurement of asphalt pavement smoothness in Florida, Transportation Research Record 1813: 62-67. http://dx.doi.org/10.3141/1813-08

Fisco, N. R. 2009. Comparison of macrotexture measurement methods. Master's Thesis. The Ohio State University. $246 \mathrm{p}$.

Fisco, N. R.; Sezen, H. 2012. Evaluation and comparison of surface macrotexture and friction measurement methods, Journal of Civil Engineering and Management 19(3): 387-399.

Flintsch, G. W.; Huang, M.; McGhee, K. 2005. Harmonization of macrotexture measuring devices, Journal of ASTM International 2(9): 1-12. http://dx.doi.org/10.1520/JAI13043

Flintsch, G. W.; Leon, E. D.; McGhee, K. K.; Al-Qadi, I. L. 2003. Pavement surface macrotexture measurement and application, Transportation Research Record 1860: 168177. http://dx.doi.org/10.3141/1860-19

Hoerner, T. E.; Smith, K. D.; Larson, R. M.; Swanlund, M. E. 2003. Current practice of Portland cement concrete pavement texturing, Transportation Research Record 1860: 178-186. http://dx.doi.org/10.3141/1860-20
Kim, S.; Gopalakrishnan, K.; Ceylan, H. 2011. A simplified approach for predicting early age concrete pavement deformation, Journal of Civil Engineering and Management 17(1): 27-35. http://dx.doi.org/10.3846/13923730.2011.554003

Kutay, M. E.; Aydilek, H. A. 2007. Dynamic effects on moisture transport in asphalt concrete, ASCE Journal of Transportation Engineering 133(7): 406-414. http://dx.doi.org/10.1061/(ASCE)0733-947X(2007)133:7 (406)

Meegoda, J. N.; Rowe, G. M.; Jumikis, A. A.; Hettiarachchi, C. H.; Bandara, N.; Gephart, N. C. 2005. Estimation of surface macrotexture in hot mix asphalt concrete pavements using laser data, ASTM Journal of Testing and Evaluation 33(5): 1-11.

Moore, D. S.; McCabe, G. P.; Craig, B. A. 2009. Introduction to the Practice of Statistics. $6^{\text {th }}$ ed. New York: W.H. Freeman and Company.

Prowell, B. D.; Hanson, D. I. Evaluation of circular texture meter for measuring surface texture of pavements, Transportation Research Record 1929: 88-96.

Sezen, H.; Fisco, N.; Luff, P. 2008. Validation of ODOT's laser macrotexture system. Ohio Department of Transportation, Columbus, Ohio. 117 p.

Wang, W.; Yan, X. P.; Huang, H.; Chu, X.; Abdel-Aty, M. 2011. Design and verification of a laser based device for pavement macrotexture measurement, Transportation Research, Part C 19: 682-694.

http://dx.doi.org/10.1016/j.trc.2010.12.001

Nicholas FISCO. A structural engineer with the TranSystems Corporation in Cleveland, Ohio, USA. He received his Master's degree from the Ohio State University in 2009.

Halil SEZEN. An Associate Professor in the Department of Civil, Environmental and Geodetic Engineering at the Ohio State University, Columbus, Ohio, USA. He got his BSc, MSc and PhD degrees from the Middle East Technical University, Ankara, Turkey; Cornell University, New York; and University of California, Berkeley, respectively. 